\title{
Exploring functional impairment in young people at ultra- high risk for psychosis: a qualitative study
}

Running title: Functioning in UHR: a qualitative study

Jack Cotter ${ }^{1,2 *}$, Sandra Bucci ${ }^{1}$, Richard J. Drake ${ }^{1}$, Alison R. Yung ${ }^{1,3}$, Rebekah Carney ${ }^{1}$, Dawn Edge ${ }^{1}$

\section{Author affiliations}

${ }^{1}$ Division of Psychology and Mental Health, Faculty of Biology, Medicine and Health, University of Manchester, Manchester, UK

${ }^{2}$ Cambridge Cognition, Cambridge, UK

${ }^{3}$ Greater Manchester West Mental Health NHS Foundation Trust, Manchester, UK

\section{*Corresponding author}

Jack Cotter, Cambridge Cognition, Tunbridge Court, Bottisham, Cambridge, CB25 9TU, United Kingdom.

Tel: +44 (0)1223 810 700; Email: jack.cotter@camcog.com

Word count abstract: 228

Word count paper: 3000

Number of tables: 3

Number of figures: 1

This is the author manuscript accepted for publication and has undergone full peer review but has not been through the copyediting, typesetting, pagination and proofreading process, which may lead to differences between this version and the Version of Record. Please cite this article as doi: $10.1111 /$ eip.12560

This article is protected by copyright. All rights reserved. 


\section{Acknowledgements}

We would like to thank the participants and all of the staff at the EDIT services that assisted in recruitment for this study.

This article is protected by copyright. All rights reserved. 


\title{
Exploring functional impairment in young people at ultra- high risk for psychosis: a qualitative study
}

\begin{abstract}
Aim: Many young people at ultra-high risk (UHR) of developing psychosis exhibit marked and persistent impairments in social and occupational functioning. We aimed to explore UHR patients' subjective experiences of these difficulties and their causes.
\end{abstract}

Methods: We conducted semi-structured interviews with twenty UHR individuals recruited from Early Detection and Intervention Teams in the Northwest of England. Topics covered included how participants spent their time, their interpersonal relationships, academic and occupational performance, premorbid functioning and clinical treatment. Thematic analysis was used to examine the prevailing themes.

Results: The sample included individuals with varying degrees of functional impairment, ranging from mild to severe difficulties in functioning. Analysis of the qualitative data elicited themes around two topics; breadth of functional difficulties and subjective reasons for poor functioning. Participants reported a range of impairments in their social and occupational functioning which they attributed to a combination of clinical, cognitive and psychological factors. These included variables previously identified in the quantitative literature such as psychiatric symptoms, adverse life experiences and cognitive deficits. However, our findings also included other factors which have received comparably little attention such as selfstigmatising attitudes and dysfunctional metacognitive beliefs. 
Conclusions: We propose a model that attempts to explain how these variables interact to drive and sustain functional impairment in the UHR population. This will assist in the development of clinical interventions aimed at promoting functional recovery among UHR individuals.

Key words: At-risk mental state; Functioning; Psychosis; Qualitative; Ultra-high risk

\section{Introduction}

People who meet criteria indicating that they are at ultra-high risk (UHR) of developing a psychotic disorder typically report poor quality of life and exhibit marked impairments in their social and occupational functioning (Fusar-Poli et al., 2015; Olvet et al., 2015; Yung et al., 1996). This includes a breakdown in peer and family relationships, vocational performance and normal daily activities (Byrne \& Morrison, 2010; Hodgekins et al., 2015). Functional impairments usually occur in adolescence or early adulthood, an important time in a young person's life for forming relationships, finishing education and starting a career (Velthorst et al., 2010). There is evidence that a large proportion of UHR individuals continue to function poorly in the long-term regardless of symptomatic remission or transition to full-threshold psychotic disorder (Addington et al., 2011; Cotter et al., 2017a; Schlosser et al., 2012). However, there is substantial variability in functional outcome in this group, suggesting a need to further investigate why some individuals continue to function poorly and others do not.

The identification of variables predictive of poor long-term functioning has become an important area of interest in the UHR group (Cotter et al., 2014). Recent 
quantitative studies have reported that negative and disorganised symptoms, neurocognitive deficits and childhood trauma are among the strongest predictors of poor functional outcome in this population (Carrión et al., 2013; Kraan et al., 2017; Lin et al., 2011; Yung et al., 2015). There is also evidence suggesting that social cognitive deficits, particularly in theory of mind (ToM), may be associated with functional impairment (Barbato et al., 2013; Cotter et al., 2017b). However, many of the mechanisms involved remain poorly understood, such as the link between childhood trauma and poor long-term functional outcome (Cotter et al., 2017a; Kraan et al., 2017; Yung et al., 2015). Further research is needed to broaden our understanding of these relationships and to identify additional factors that potentially contribute to poor functioning in this population in order to inform the development of more targeted interventions.

Qualitative research provides a tool for gaining insight into functional impairment through discussion of individuals' personal experiences. In the few qualitative studies that have examined functioning in UHR individuals, participants have voiced difficulties in their interpersonal relationships and expressed dissatisfaction with their social situation (Byrne \& Morrison, 2010; Ben-David et al., 2014). However, these studies did not examine why individuals felt this was the case or what they felt could be done to help. In this study, we aimed to explore patients' subjective experiences of these functional difficulties and their perceived causes.

\section{Methods}

\section{Participants}


Twenty participants were recruited from Early Detection and Intervention Team (EDIT) services in Northwest England. In order to be accepted into these services patients must be aged between 14-35 years, be help-seeking and meet UHR criteria according to the Comprehensive Assessment of At-Risk Mental States (CAARMS) (Yung et al., 2005). Patients eligible for inclusion in this study were aged 16-35 and were fluent English speakers. The Greater Manchester West National Health Service Research Ethics Committee approved the study (ref:15/NW/0705). All patients provided written informed consent prior to their participation.

\section{Procedure and assessments}

Patients were initially approached with information about the study by their clinician. The contact details of patients who expressed an interest in participating were forwarded to the research team who arranged a suitable time and mutually convenient location to meet. All interviews and assessments were conducted by the lead author (J.C.). Participants were reimbursed for their time.

\section{Demographic information}

Participants' age, gender, ethnicity, marital, vocational and living status and their highest educational qualification at the time of the assessment were recorded.

Psychopathology 
All participants were assessed with the CAARMS (Yung et al., 2005). None had developed full-threshold psychotic symptoms at the time of the interview. Positive symptoms were also assessed using the Brief Psychiatric Rating Scale (BPRS) psychotic subscale (Overall \& Gorham, 1962). Negative symptoms were assessed using the Scale for the Assessment of Negative Symptoms (SANS) (Andreasen, 1984). Depression was assessed with the Beck Depression Inventory (BDI-II) (Beck, Steer, \& Brown, 1996).

\section{Functioning}

The Personal and Social Performance scale (PSP) was used to assess social and occupational functioning over the past month (Morosini et al., 2000). This is an observer-rated 100-point single-item rating scale. It has anchor points at the deciles which are based on functioning in four main areas: 1) socially useful activities, including work and study; 2) personal and social relationships; 3) self-care; and 4) disturbing and aggressive behaviours. Higher scores indicate better functioning.

\section{Social cognition and childhood trauma}

Theory of Mind was assessed using the Reading the Mind in the Eyes test (BaronCohen et al., 2001). Participants are presented with 36 pictures of people's eyes and asked to select the most accurate descriptor for their thoughts/feelings from a list of 4 options. History of childhood maltreatment was assessed using the brief Childhood Trauma Questionnaire (CTQ) (Bernstein et al., 2003), a 28-item self-report instrument that assesses childhood experiences of physical abuse and neglect, 
sexual abuse and emotional abuse and neglect and provides a total score for overall trauma. The CTQ is routinely administered in the participating clinical services, therefore data were acquired from participants' medical records.

\section{Qualitative interviews}

We adopted a thematic approach, using qualitative individual interviews. Each interview lasted between 30-45 minutes, was audio-recorded and subsequently transcribed verbatim. A semi-structured interview format was used and was directed by the study topic guide (available on request). This was developed based on a systematic review of the UHR functioning research literature and the clinical expertise of the research team (Cotter et al., 2014). The topic guide covered a range of different aspects of social and occupational functioning including time use, interpersonal relationships, vocational engagement, premorbid functioning and clinical treatment. A series of key questions were asked to all participants (e.g. "What is a typical day for you?", "How are you getting on with other people at the moment?"); however, the topic guide was flexible and allowed participants to discuss topics that were pertinent to them. Participants were encouraged to talk openly about their views and experiences, with the interviewer facilitating conversation with initial open questions and further prompts as necessary. After twenty participants had been interviewed, no new themes emerged and recruitment stopped.

\section{Data analysis}


Qualitative data were analysed using thematic analysis. This is a systematic but flexible approach that involves coding and establishing themes within the data in order to identify similarities and differences among participant accounts (Braun \& Clarke, 2006). While we had prior knowledge about what drives poor functioning on the basis of previous quantitative studies, we attempted to generate codes in a 'bottom-up' manner directly from the transcripts in order to identify novel factors. NVivo qualitative software package was used to support data management and analysis. The thematic analysis was conducted in the following stages (as recommended by Braun \& Clarke, 2006);

1. Transcripts were read and re-read to familiarise the researchers with the data

2. Systematic line by line coding of interesting features of the data

3. Codes were collated and combined into potential themes

4. Themes were reviewed to ensure they were internally coherent, consistent and distinctive

5. Themes were refined, with names and definitions generated for each

6. Important quotes were extracted from the transcripts that encapsulated these themes

All of the transcripts were analysed by the lead author (J.C.). In addition, two of the other authors (S.B. and D.E.) with extensive experience in qualitative methodology independently reviewed and coded three transcripts each in an effort to minimise bias in the interpretation of the data. All members of the research team rigorously reviewed the research process. This peer verification process is a recognised method of ensuring 'trustworthiness' of the data and subsequent findings (Gibson \& Brown, 2009). 


\section{Results}

An overview of the characteristics of the sample are provided in Tables 1 and 2. The sample included individuals with varying degrees of functional impairment, ranging from mild to severe difficulties in functioning. Analyses of the qualitative data elicited themes around two topics; breadth of functional difficulties and subjective reasons for poor functioning.

\section{[Insert Tables 1 and 2 here]}

\section{Breadth of functional difficulties}

Interpersonal relationships

Participants presented with a range of impairments in their social and occupational functioning. Participants reported diminished sociability, loss of friendships, lack of interests and generally supportive but strained family relationships.

"I think it's made me more distant from friends and stuff. Which, most of them have taken personally. So yeah, I think it's distanced me a bit from other people. They've thought I've fallen out with them when really it's just, something I can't communicate." [P11]

Time use

This article is protected by copyright. All rights reserved. 
Participants suggested that their time use was often poor and unstructured. Many individuals reported sleeping for a large proportion of the day and spending most of their time playing online computer games, often until the early hours of the morning. Even among those who were enrolled as college or university students, attendance and engagement was frequently poor with most citing sliding grades as a consequence.

\begin{abstract}
"At the minute it's just find something to do, video games, whatever, just kinda continue existing. It's very much just a case of continuing to exist, I don't really get much done." [P8]
\end{abstract}

\title{
Functional trajectory
}

The specific aspects and trajectory of functional impairment varied widely between individuals. Some reported experiencing difficulties as far back as they could remember, while others reported a progressive deterioration over the preceding months.

\footnotetext{
"I didn't have that many friends at school. I felt like a bit of an outsider that didn't really fit in." [P9]

"I don't know, it's different to what I was used to because I was never like that. I used to be the person that you heard before they even walked into the room and then I don't know where it came from. It's like the complete opposite to what it was." [P7]
}

\section{Functioning as a treatment target}

Despite exhibiting marked functional impairment, many individuals did not consider this to be a priority target for clinical treatment. Poor social functioning was seen by 
some as part of their identity, while others considered it as something they needed to manage for themselves.

"It's a weird thing that I feel like I should be better at it [socialising] but I'm not fussed over it. Like l've always been the kid that's not got friends so l've just accepted that's who I am." [P4]

\section{Future aspirations}

Despite their problems, most of the participants maintained hope for the future and held a number of career and lifestyle aspirations. These typically focused around what they perceived to be living a 'normal life'; overcoming their current mental health problems and establishing a good career.

"I want to get up in the morning, go to work, come home, have me tea, put me feet up, chill. It sounds boring but in my head that's enough, getting up in the morning going and doing my work and coming home. I just want a normal life." $[\mathrm{P} 7]$

\section{Subjective reasons for poor functioning}

\section{Exposure to adverse experiences}

Adverse experiences, particularly exposure to bullying, neglect and abuse in childhood but also victimization in adulthood, were also believed by many of the participants to have played a causal role in the development of their symptoms and their interpersonal and academic difficulties. Mistrust of others, fear of judgement, 
social withdrawal and depression were all reported by participants to have arisen as a direct result of these adverse life experiences.

"I deal with it [previous history of childhood physical and sexual abuse], but yeah it probably does affect me. I think more in terms of relationships; I don't let anyone get near me. l'd rather be on my own forever, I feel like no one will ever get in...It's not nice to go through life thinking about negative stuff. I'd love to get married and have kids and have that life, but it's whether you can let somebody in so that they can get close enough." [P19]

\section{Clinical symptoms}

Negative symptoms, such as a lack of motivation and social withdrawal, were frequently cited as reasons for loss of friendships, academic problems and diminished sociability.

“I haven't got the drive [to go to college] and also, I don't know how to explain it, it's almost like, kind of going back to the don't want to be seen, don't want to talk to anyone. I guess it's easier to hide than it is to go. You know, you need to talk, you need to smile, that can be exhausting if you're not in the right frame of mind" [P6]

Positive psychotic symptoms (including both suspiciousness and hallucinations) and social anxiety were also very common and widely considered to be barriers to functional recovery.

"If the voices come then I just go home, I won't go out anywhere, like nowhere. I just want to be in the house." [P3]

Self-stigma 
There was evidence that stigma, particularly self-stigmatising attitudes, impeded functioning. Many individuals feared they would be viewed as 'weird' by others due to their symptoms and isolated themselves as a consequence.

"I want to get a job. But now it's the voices and the fear of actually going into the work place, I'm not going to know anybody. I'll feel like they're talking about me, or know I'm hearing things and they'll think I'm weird. So at the minute I have to build up to go back to work, but I would love to." [P13]

\section{Metacognitive beliefs}

Heightened self-focused attention and repetitive rumination (particularly around fear of experiencing anxiety or embarrassment) often led to individuals avoiding social situations, including social events, college and university lectures, which in turn had implications for their interpersonal relationships and academic performance.

"[l get anxious about] mostly social things and like, crowds and what people think of me when they see me, that kind of thing... But mostly just overthinking, worrying that if I think this then that might happen, and I can't do things because of that. ... Things that when I think about it sound stupid, but in the moment it's very real to me" [P11]

\section{Cognition}

Subjective neurocognitive and social cognitive difficulties were common, even in the absence of objective deficits on the ToM task. These were also reported by a number of individuals to have contributed to social and vocational problems they had experienced. 
“I don't know how to behave. It sounds weird, but I don't know whether to be serious around them, whether to be relaxed or how to make conversation with them and stuff... Like my friend was telling me something the other day and I thought she was messing about, so I started laughing and she said "I'm being serious" and she fell out with me over it... I find it really hard to read people's emotions. Unless it's really obviously; if they're crying I know they're upset, but if they're upset and they're not making it obvious then I won't know." [P12]

\section{[Insert Table 3 here]}

\section{Discussion}

\section{Overview of findings}

We adopted a qualitative approach to investigate functioning in the UHR group. Participants attributed their functional difficulties to a number of factors, many of which have previously been identified in the quantitative literature such as clinical symptoms, cognitive deficits and adverse and traumatic life experiences (Meyer et al., 2014; Kraan et al., 2017; Lin et al., 2011). Self-stigmatising and dysfunctional metacognitive beliefs also emerged as themes and were frequently cited as barriers to engaging in social and vocational activities. These have received comparatively little attention in previous studies investigating functioning in the UHR group.

Based on the themes derived from this study and previous quantitative research (Cotter et al., 2014; Yung et al., 2015), we have proposed a model that attempts to highlight the main factors driving functional impairment in the UHR group (Figure 1). 
In this model, clinical symptoms and cognitive deficits have a direct effect on social and occupational functioning. The detrimental impact of these factors on functioning are maintained and potentially exacerbated by dysfunctional metacognitive and selfstigmatising beliefs. This can lead to low self-esteem and poor self-efficacy that further inhibits individuals from engaging in social and occupational activities. A reciprocal loop may form that drives long-term functional disability. Exposure to adverse life events such as bullying or abuse (that may occur in childhood or adulthood and also reflect ongoing revictimization) may play a causal role in the onset and persistence of psychiatric symptoms and also have damaging implications for other aspects of psychological well-being, such as self-esteem, further contributing to functional decline.

\section{[Insert Figure 1 here]}

\section{Clinical implications}

Treatments to date in the UHR group have focused on reducing subthreshold positive symptoms, preventing transition to psychotic disorder, and managing current symptoms (McGlashan et al., 2007; Stafford et al., 2013). However, these have been shown to be largely ineffective at promoting functional recovery (Schmidt et al., 2015; van der Gaag et al., 2013). There is a need to develop more targeted approaches to clinical intervention that focus on improving functioning as a primary outcome. A trial of Social Recovery Cognitive Behavioural Therapy (SRCBT) is currently underway in the UHR group that seeks to increase time engaged in 
structured activity (such as work or study) by targeting many of the mechanisms identified in this paper, such as social anxiety and negative symptoms (Fowler et al., 2017). Addressing unhelpful metacognitive and self-stigmatising beliefs may also assist in improving functioning in this population. Consistent with recent quantitative research, participants self-stigmatising attitudes appeared to be associated predominantly with their symptoms as opposed to any clinical 'label' (Yang et al., 2015). Many participants complained about 'overthinking' and exhibited a preoccupation with worry associated with their clinical symptoms which resulted in them avoiding social situations. Such beliefs are common in the UHR group (Cotter, Yung, Carney, \& Drake, 2017), suggesting strategies shown to reduce worry and modify maladaptive beliefs may be useful (Freeman et al., 2015; Morrison et al., 2014).

Exposure to adverse and traumatic experiences, particularly in childhood but also in adulthood, was highlighted as an important patient-perceived reason for functional impairment. This emphasises the importance of assessing traumatic childhood experiences and ongoing abuse in adulthood in individuals presenting to mental health services (Cotter, Drake, \& Yung, 2016; Cotter, Kaess, \& Yung, 2015; Hovens et al., 2012; Varese et al., 2012). Treatments aimed at alleviating psychological dysfunction associated with trauma have been shown to be effective in people with full-threshold psychotic disorder (van den Berg et al., 2015). This study and previous research in this area suggest similar approaches are warranted in the UHR group and may confer benefits for both functional and symptomatic outcomes (Cotter et al., 2017a; Kraan et al., 2017). 


\section{Strengths and limitations}

This study involved detailed exploration of social and occupational functioning in the UHR group and is among the largest qualitative studies conducted in this population to date. Our sample included a diverse cross-section of individuals with different clinical profiles and varying degrees of functional impairment. We adopted a convenience sampling approach which led to an equal number of males and females in our sample, all of whom identified as being White and were fluent English speakers. This was representative of this particular clinical service but should be an important consideration before generalizing these findings to other ethnic groups. Future research could also extend the current study by including the views of family members and carers, clinicians and those UHR individuals who are no longer using services.

\section{References}

Addington, J., Cornblatt, B. A., Cadenhead, K. S., Cannon, T. D., McGlashan, T. H., Perkins, D. O., et al. (2011). At clinical high risk for psychosis: outcome for nonconverters. American Journal of Psychiatry, 168(8), 800-805. doi:10.1176/appi.ajp.2011.10081191

Andreasen, N. C. (1984). Scale for the Assessment of Negative Symptoms. Iowa City, lowa: University of lowa Press.

Barbato, M., Liu, L., Penn, D. L., Keefe, R. S., Perkins, D. O., Woods, S. W., et al. (2013). Social cognition as a mediator between neurocognition and functional outcome in individuals at clinical high risk for psychosis. Schizophrenia Research, 150(2-3), 542-546. doi:10.1016/j.schres.2013.08.015

Baron-Cohen, S., Wheelwright, S., Hill, J., Raste, Y., \& Plumb, I. (2001). The "Reading the Mind in the Eyes" Test revised version: a study with normal adults, and adults with Asperger syndrome or high-functioning autism. Journal of Child Psychology and Psychiatry, 42(2), 241-251. 
Beck, A. T., Steer, R. A., \& Brown, G. K. (1996). Manual for the Beck Depression Inventory-II. San Antonio, TX: Psychological Corporation.

Ben-David, S., Birnbaum, M. L., Eilenberg, M. E., DeVylder, J. E., Gill, K. E., Schienle, J., et al. (2014). The subjective experience of youths at clinically high risk of psychosis: a qualitative study. Psychiatric Services, 65(12), 1499-1501. doi:10.1176/appi.ps.201300527

Bernstein, D. P., Stein, J. A., Newcomb, M. D., Walker, E., Pogge, D., Ahluvalia, T., et al. (2003). Development and validation of a brief screening version of the Childhood Trauma Questionnaire. Child Abuse \& Neglect, 27(2), 169-190.

Braun, V., \& Clarke, V. (2006). Using thematic analysis in psychology. Qualitative Research in Psychology, 3(2), 77-101. doi:10.1191/1478088706qp063oa

Byrne, R., \& Morrison, A. P. (2010). Young people at risk of psychosis: a user-led exploration of interpersonal relationships and communication of psychological difficulties. Early Intervention in Psychiatry, 4(2), 162-168. doi:10.1111/j.17517893.2010.00171

Carrión, R. E., McLaughlin, D., Goldberg, T. E., Auther, A. M., Olsen, R. H., Olvet, D. $\mathrm{M}$., et al. (2013). Prediction of functional outcome in individuals at clinical high risk for psychosis. JAMA Psychiatry, 70(11), 1133-1142. doi:10.1001/jamapsychiatry.2013.1909

Cotter, J., Bartholomeusz, C., Papas, A., Allott, K., Nelson, B., Yung, A. R., et al. (2017b). Examining the association between social cognition and functioning in individuals at ultra-high risk for psychosis. Australian and New Zealand Journal of Psychiatry, 51(1), 83-92. doi:10.1177/0004867415622691

Cotter, J., Drake, R. J., Bucci, S., Firth, J., Edge, D., \& Yung, A. R. (2014). What drives poor functioning in the at-risk mental state? A systematic review. Schizophrenia Research, 159(2-3), 267-277. doi:10.1016/j.schres.2014.09.012

Cotter, J., Drake, R. J., \& Yung, A. R. (2016). Adulthood revictimization: looking beyond childhood trauma. Acta Psychiatrica Scandinavica, 134(4), 368. doi:10.1111/acps.12602

Cotter, J., Kaess, M., \& Yung, A. R. (2015). Childhood trauma and functional disability in psychosis, bipolar disorder and borderline personality disorder: a review of the literature. Irish Journal of Psychological Medicine, 32(1), 21-30. doi:10.1017/ipm.2014.74

Cotter, J., Lin, A., Drake, R. J., Thompson, A., Nelson, B., McGorry, P., et al. (2017a). Long-term employment among people at ultra-high risk for psychosis. Schizophrenia Research, 184, 26-31. doi:10.1016/j.schres.2016.11.033 
Cotter, J., Yung, A. R., Carney, R., \& Drake, R. J. (2017). Metacognitive beliefs in the at-risk mental state: a systematic review and meta-analysis. Behaviour Research and Therapy, 90, 25-31. doi:10.1016/j.brat.2016.12.004

Fowler, D., French, P., Banerjee, R., Barton, G., Berry, C., Byrne, R., et al. (2017). Prevention and treatment of long-term social disability amongst young people with emerging severe mental illness with social recovery therapy (The PRODIGY Trial): study protocol for a randomised controlled trial. Trials, 18(1), 315. doi:10.1186/s13063-017-2062-9

Freeman, D., Dunn, G., Startup, H., Pugh, K., Cordwell, J., Mander, H., et al. (2015). Effects of cognitive behaviour therapy for worry on persecutory delusions in patients with psychosis (WIT): a parallel, single-blind, randomised controlled trial with a mediation analysis. Lancet Psychiatry, 2(4), 305-313. doi:10.1016/S22150366(15)00039-5

Fusar-Poli, P., Rocchetti, M., Sardella, A., Avila, A., Brandizzi, M., Caverzasi, E., et al. (2015). Disorder, not just state of risk: meta-analysis of functioning and quality of life in people at high risk of psychosis. British Journal of Psychiatry, 207(3), 198-206. doi:10.1192/bjp.bp.114.157115

Gibson, W., \& Brown, A. (2009). Working with Qualitative Data. London: Sage.

Hodgekins, J., French, P., Birchwood, M., Mugford, M., Christopher, R., Marshall, M., et al. (2015). Comparing time use in individuals at different stages of psychosis and a non-clinical comparison group. Schizophrenia Research, 161(2-3), 188-193. doi:10.1016/j.schres.2014.12.011

Hovens, J. G., Giltay, E. J., Wiersma, J. E., Spinhoven, P., Penninx, B. W., \& Zitman, F. G. (2012). Impact of childhood life events and trauma on the course of depressive and anxiety disorders. Acta Psychiatrica Scandinavica, 126(3), 198-207. doi:10.1111/j.1600-0447.2011.01828

Kraan, T. C., Ising, H. K., Fokkema, M., Velthorst, E., van den Berg, D. P. G., Kerkhoven, M., et al. (2017). The effect of childhood adversity on 4-year outcome in individuals at ultra high risk for psychosis in the Dutch Early Detection Intervention Evaluation (EDIE-NL) Trial. Psychiatry Research, 247, 55-62. doi:10.1016/j.psychres.2016.11.014

Lin, A., Wood, S. J., Nelson, B., Brewer, W. J., Spiliotacopoulos, D., Bruxner, A., et al. (2011). Neurocognitive predictors of functional outcome two to 13 years after identification as ultra-high risk for psychosis. Schizophrenia Research, 132(1), 1-7. doi:10.1016/j.schres.2011.06.014

McGlashan, T. H., Addington, J., Cannon, T., Heinimaa, M., McGorry, P., O'Brien, M., et al. (2007). Recruitment and treatment practices for help-seeking "prodromal" patients. Schizophrenia Bulletin, 33(3), 715-726. 
Meyer, E. C., Carrión, R. E., Cornblatt, B. A., Addington, J., Cadenhead, K. S., Cannon TD., et al. (2014). The relationship of neurocognition and negative symptoms to social and role functioning over time in individuals at clinical high risk in the first phase of the North American Prodrome Longitudinal Study. Schizophrenia Bulletin, 40(6), 1452-1461. doi:10.1093/schbul/sbt235

Morosini, P. L., Magliano, L., Brambilla, L., Ugolini, S., \& Pioli, R. (2000). Development, reliability and acceptability of a new version of the DSM-IV Social and Occupational Functioning Assessment Scale (SOFAS) to assess routine social functioning. Acta Psychiatrica Scandinavica, 101(4), 323-329.

Morrison, A. P., Pyle, M., Chapman, N., French, P., Parker, S. K., \& Wells, A. (2014). Metacognitive therapy in people with a schizophrenia spectrum diagnosis and medication resistant symptoms: a feasibility study. Journal of Behavior Therapy and Experimental Psychiatry, 45(2), 280-284. doi:10.1016/j.jbtep.2013.11.003

Olvet, D. M., Carrión, R. E., Auther, A. M., \& Cornblatt, B. A. (2015). Self-awareness of functional impairment in individuals at clinical high-risk for psychosis. Early Intervention in Psychiatry, 9(2), 100-107. doi:10.1111/eip.12086

Overall, J. E., \& Gorham, D. R. (1962). The Brief Psychiatric Rating Scale. Psychological Reports, 10, 799-812.

Schlosser, D. A., Jacobson, S., Chen, Q., Sugar, C. A., Niendam, T. A., Li, G., et al. (2012). Recovery from an at-risk state: clinical and functional outcomes of putatively prodromal youth who do not develop psychosis. Schizophrenia Bulletin, 38(6), 12251233. doi:10.1093/schbul/sbr098

Schmidt, S. J., Schultze-Lutter, F., Schimmelmann, B. G., Maric, N. P., Salokangas, R. K., Riecher-Rössler, A., et al. (2015). EPA guidance on the early intervention in clinical high risk states of psychoses. European Psychiatry, 30(3), 388-404. doi:10.1016/j.eurpsy.2015.01.013

Stafford, M. R., Jackson, H., Mayo-Wilson, E., Morrison, A. P., \& Kendall, T. (2013). Early interventions to prevent psychosis: systematic review and meta-analysis. BMJ, 346, f185. doi:10.1136/bmj.f185

van den Berg, D. P., de Bont, P. A., van der Vleugel, B. M., de Roos, C., de Jongh, A., Van Minnen, A., et al. (2015). Prolonged exposure vs eye movement desensitization and reprocessing vs waiting list for posttraumatic stress disorder in patients with a psychotic disorder: a randomized clinical trial. JAMA Psychiatry, 72(3), 259-267. doi:10.1001/jamapsychiatry.2014.2637

van der Gaag, M., Smit, F., Bechdolf, A., French, P., Linszen, D. H., Yung, A. R., et al. (2013). Preventing a first episode of psychosis: meta-analysis of randomized controlled prevention trials of 12 month and longer-term follow-ups. Schizophrenia Research, 149(1-3), 56-62. doi:10.1016/j.schres.2013.07.004 
Varese, F., Smeets, F., Drukker, M., Lieverse, R., Lataster, T., Viechtbauer, W., et al. (2012). Childhood adversities increase the risk of psychosis: a meta-analysis of patient-control, prospective- and cross-sectional cohort studies. Schizophrenia Bulletin, 38(4), 661-671. doi:10.1093/schbul/sbs050

Velthorst, E., Nieman, D. H., Linszen, D., Becker, H., de Haan, L., Dingemans, P. M., et al. (2010). Disability in people clinically at high risk of psychosis. British Journal of Psychiatry, 197(4), 278-284. doi:10.1192/bjp.bp.109.075036

Yang, L. H., Link, B. G., Ben-David, S., Gill, K. E., Girgis, R. R., Brucato, G., et al. (2015). Stigma related to labels and symptoms in individuals at clinical high-risk for psychosis. Schizophrenia Research, 168(1-2), 9-15. doi:10.1016/j.schres.2015.08.004

Yung, A. R., Cotter, J., Wood, S. J., McGorry, P., Thompson, A. D., Nelson, B., et al. (2015). Childhood maltreatment and transition to psychotic disorder independently predict long-term functioning in young people at ultra-high risk for psychosis. Psychological Medicine, 45(16), 3453-3465. doi:10.1017/S003329171500135X

Yung, A. R., McGorry, P. D., McFarlane, C. A., Jackson, H. J., Patton, G. C., \& Rakkar, A. (1996). Monitoring and care of young people at incipient risk of psychosis. Schizophrenia Bulletin, 22(2), 283-303.

Yung, A. R., Yuen, H. P., McGorry, P. D., Phillips, L. J., Kelly, D., Dell'Olio, M., et al. (2005). Mapping the onset of psychosis: the Comprehensive Assessment of At-Risk Mental States. Australian and New Zealand Journal of Psychiatry, 39(11-12), 964971. 
Table 1: Sample demographic information

\begin{tabular}{|l|l|l|l|l|l|l|l}
\hline Participant & Sex & Age (years) & Ethnicity & Marital status & Employment status & Highest qualification & Living status \\
\hline 1 & Male & 19 & White & Single & Student & BTEC & Lives with family \\
\hline 2 & Male & 19 & White & Single & Unemployed & BTEC & Lives with family \\
3 & Female & 16 & White & In a relationship & Student & GCSE & Lives with family \\
\hline 4 & Female & 21 & White & In a relationship & Student & Undergraduate degree & Lives with friends \\
5 & Female & 20 & White & Single & Student & A-level & Lives with friends \\
6 & Female & 26 & White & In a relationship & Full-time employed & A-level & Lives with partner \\
\hline 7 & Male & 20 & White & Single & Unemployed & A-level & Lives with friends \\
8 & Male & 26 & White & Single & Student & Undergraduate degree & Lives with friends \\
9 & Female & 24 & White & Single & Unemployed & BTEC & Lives with family \\
10 & Male & 16 & White & Single & Student & GCSE & Lives with family \\
11 & Female & 19 & White & In a relationship & Student & BTEC & Lives with family \\
12 & Female & 17 & White & In a relationship & Student & BTEC & Bives with family \\
13 & Female & 26 & White & In a relationship & Unemployed & A-level & Lives with partner \\
14 & Male & 16 & White & Single & Student & Lamily \\
15 & Male & 21 & White & In a relationship & Part-time employed & A-level & No qualifications \\
16 & Male & 16 & White & Single & Unemployed & Lives with family \\
17 & Male & 20 & White & In a relationship & Part-time employed & GCSE & Lives on own \\
18 & Male & 20 & White & Single & Student & A-level & Lives with friends \\
19 & Female & 29 & White & Single & Full-time employed & Undergraduate degree & Lives on own \\
20 & Female & 23 & White & In a relationship & Unemployed & GCSE & Lives with partner \\
\hline
\end{tabular}

This article is protected by copyright. All rights reserved. 
Table 2: Sample assessment scores

\begin{tabular}{lll}
\hline & Mean (SD) & Range \\
\hline Time in EDIT service (weeks) & $17.0(13.0)$ & $1-48$ \\
BPRS psychotic subscale & $9.8(1.8)$ & $7-13$ \\
SANS total & $24.1(10.1)$ & $13-50$ \\
BDI-II total & $36.4(11.6)$ & $20-59$ \\
RMitE total & $22.0(4.4)$ & $14-32$ \\
CTQ total $^{*}$ & $42.3(14.2)$ & $25-62$ \\
PSP total & $58.0(13.7)$ & $37-80$ \\
\hline
\end{tabular}

* Data unavailable for $N=7$, of which two participants already had a known history of childhood sexual and physical abuse

Abbreviations: BDI-II - Beck Depression Inventory; BPRS - Brief Psychiatric Rating Scale; CTQ Childhood Trauma Questionnaire; EDIT - Early Detection and Intervention Team; PSP - Personal and Social Performance scale; RMitE - Reading the Mind in the Eyes test; SANS - Scale for the Assessment of Negative Symptoms.

This article is protected by copyright. All rights reserved. 
Table 3: Additional examples of quotes from each of the themes

\begin{tabular}{|c|c|}
\hline \multicolumn{2}{|c|}{ Breadth of functional difficulties } \\
\hline \multirow[t]{4}{*}{$\begin{array}{l}\text { Interpersonal } \\
\text { relationships }\end{array}$} & $\begin{array}{l}\text { "My mum... I try to get on with her but we clash... like if we have a little } \\
\text { argument about something it turns into a massive scene." [P12] }\end{array}$ \\
\hline & $\begin{array}{l}\text { "I get on with them [family] yeah. I've had my ups and downs. Nearly had } \\
\text { fights with my dad and my brother." [P16] }\end{array}$ \\
\hline & $\begin{array}{l}\text { "I hardly speak to most people now. Like my family, I only go and see my } \\
\text { family every now and then. Don't get on with them all at all." [P17] }\end{array}$ \\
\hline & $\begin{array}{l}\text { "I think as the year's gone on l've got more distant from some of the people } \\
\text { who were close to me. Lately l've drifted apart from people and lost } \\
\text { interest." [P20] }\end{array}$ \\
\hline \multirow[t]{3}{*}{ Time use } & $\begin{array}{l}\text { "Wake up at me mates, and then probably have a cig and get ready, then } \\
\text { come straight back down to me mums... then normally go and sit in my } \\
\text { room for a bit on my own for a couple of hours, then go back up to my } \\
\text { mates and sit with them in the living room, that's it at the minute. It's a } \\
\text { boring life." [P7] }\end{array}$ \\
\hline & $\begin{array}{l}\text { "It's normally about lunchtime that I get up. I don't usually go to bed until } \\
\text { the early hours of the morning... Then normally eat something and then } \\
\text { just go on the computer for a bit. Then depending on how l'm feeling, I'll } \\
\text { either stay at home all day or go out. Sometimes I don't feel that motivated } \\
\text { to go out." [P9] }\end{array}$ \\
\hline & $\begin{array}{l}\text { "I'll wake up in the morning, I'll have about eight alarms set, they'll wake me } \\
\text { up and by the time the eighth alarm is finished l'll go straight back to bed. } \\
\text { Usually miss the first three hours of my lectures, then l'll turn up for the last } \\
\text { couple of hours and then l'll either go to the pub or to the shop to buy } \\
\text { alcohol." [P18] }\end{array}$ \\
\hline \multirow[t]{2}{*}{ Functional trajectory } & $\begin{array}{l}\text { "I think personally l've always been distant with people. I think over the past } \\
\text { year l've been getting worse." [P15] }\end{array}$ \\
\hline & $\begin{array}{l}\text { "I've never really had friends. I had friends in school because I had to go } \\
\text { there, but even then, I didn't really talk to them. I was the one that just sat } \\
\text { there and listened. I didn't see any of them outside school or anything." } \\
\text { [P20] }\end{array}$ \\
\hline \multirow[t]{2}{*}{$\begin{array}{l}\text { Functioning as a } \\
\text { treatment target }\end{array}$} & $\begin{array}{l}\text { "It's [targeting functional difficulties during CBT sessions] not really } \\
\text { something I'm doing at the moment because I feel like, it can be really on } \\
\text { and off and I'll have days where it doesn't bother me at all, I just have my } \\
\text { bad days where I can't go in and stuff." [P5] }\end{array}$ \\
\hline & $\begin{array}{l}\text { "I'm taking a break from looking for jobs at the moment while l'm having } \\
\text { therapy. Then once that's done l'll think about starting to look for jobs } \\
\text { again." [P9] }\end{array}$ \\
\hline \multirow[t]{3}{*}{ Future aspirations } & "I want to go out and make something of myself." [P2] \\
\hline & $\begin{array}{l}\text { "I would love to go back to going back out and socialising, and take my kids } \\
\text { to school... hopefully either go back to college or be able to get a job." } \\
\text { [P13] }\end{array}$ \\
\hline & $\begin{array}{l}\text { "Now l've got help, I see myself with a job, supporting us as much as my } \\
\text { fella is, driving, going on holidays." [P20] }\end{array}$ \\
\hline
\end{tabular}




\begin{tabular}{|c|c|}
\hline \multicolumn{2}{|c|}{ Subjective reasons for poor functioning } \\
\hline \multirow[t]{3}{*}{$\begin{array}{l}\text { Exposure to adverse } \\
\text { experiences }\end{array}$} & $\begin{array}{l}\text { "My dad was not the most supportive person. Ummm, yeah it's one of } \\
\text { those things where you look back and think I'm sure loads of people had it } \\
\text { worse than me, but after having spoken to people I think it was emotional } \\
\text { abuse I suffered as a child... I think that's where I've got my 'I can't rely on } \\
\text { other people' thinking from. Because I couldn't rely on my dad to look after } \\
\text { me so I kind of had to look after myself." [P4] }\end{array}$ \\
\hline & $\begin{array}{l}\text { "I used to be quite good in school, then the bullying started and it carried on } \\
\text { and it made me worse [more depressed], it just made me not want to carry } \\
\text { on and do anything. Then I just didn't pass anything really. My attendance } \\
\text { was terrible. I didn't go in. I'm pretty sure I didn't go in for nearly a month. I } \\
\text { wouldn't go in, I just refused." [P15] }\end{array}$ \\
\hline & $\begin{array}{l}\text { "Bullying, it's messed with me really. I didn't used to be like this [socially } \\
\text { reclusive] until the bullying happened, then it just messed me up." [P16] }\end{array}$ \\
\hline \multirow[t]{2}{*}{ Clinical symptoms } & $\begin{array}{l}\text { "I think mainly because I'm really anxious. I struggle to initially talk to } \\
\text { people, then when I do I'm always the weird kid who's really silent and } \\
\text { stuff. I've always been a bit depressed, I've always been anxious, so going } \\
\text { and talking to people is a really, really hard thing to do for me, and the idea } \\
\text { of making new friends, I'm really pessimistic about." [P4] }\end{array}$ \\
\hline & $\begin{array}{l}\text { "I think it's just that I don't have the motivation to do anything, so I think that } \\
\text { makes me feel tired. I just don't feel like doing anything". [P14] }\end{array}$ \\
\hline \multirow[t]{2}{*}{ Self-stigma } & $\begin{array}{l}\text { "I'm just scared with like, going up to someone and making friends, but } \\
\text { them judging me for the way I am now. It's hard making conversation with } \\
\text { people that you don't know, then you have the voices saying things to you } \\
\text { and you don't want to say the wrong thing out loud and have them thinking } \\
\text { you're some sort of weirdo." [P3] }\end{array}$ \\
\hline & $\begin{array}{l}\text { Like I don't want to interact with people in case they think that I'm weird... } \\
\text { like if something happened, or they noticed that something was going on." } \\
\text { [P11] }\end{array}$ \\
\hline \multirow[t]{2}{*}{ Metacognitive beliefs } & $\begin{array}{l}\text { "I really lack perspective when it comes to other people, l'm always like } \\
\text { worst-case scenario, everything's going to go wrong, something bad's } \\
\text { going to happen." [P4] }\end{array}$ \\
\hline & $\begin{array}{l}\text { "I want to go out and do stuff with other people, and I do feel better when I } \\
\text { do it. It's just I can't. It's so hard to explain. I have no motivation and just } \\
\text { the worries. I'll arrange something with someone, then I'll sit and think } \\
\text { about it, then at the last second I'll say no and I'll cancel it. It's the 'what } \\
\text { if's', what if this happens, what if she doesn't turn up, stuff like that." [P20] }\end{array}$ \\
\hline \multirow[t]{2}{*}{ Cognition } & $\begin{array}{l}\text { "I have a terrible memory and I find it really hard to concentrate on things. } \\
\text { Like say if I'm at college, if I read something I need to read it again and } \\
\text { again to make sure it goes in. I struggle to understand things, like I'll try } \\
\text { and concentrate on something, read it, but it won't go in, I can't get it." } \\
\text { [P12] }\end{array}$ \\
\hline & $\begin{array}{l}\text { "My memory's just gone completely... people get really annoyed because I } \\
\text { make plans and then they'll ring me like "where are you?" and l've } \\
\text { completely forgot we were supposed to be meeting. It happens all the time } \\
\text { at the minute. I'm surprised l've got any mates left. It's constant." [P19] }\end{array}$ \\
\hline
\end{tabular}


Figure 1. Factors contributing to functional impairment in the UHR group

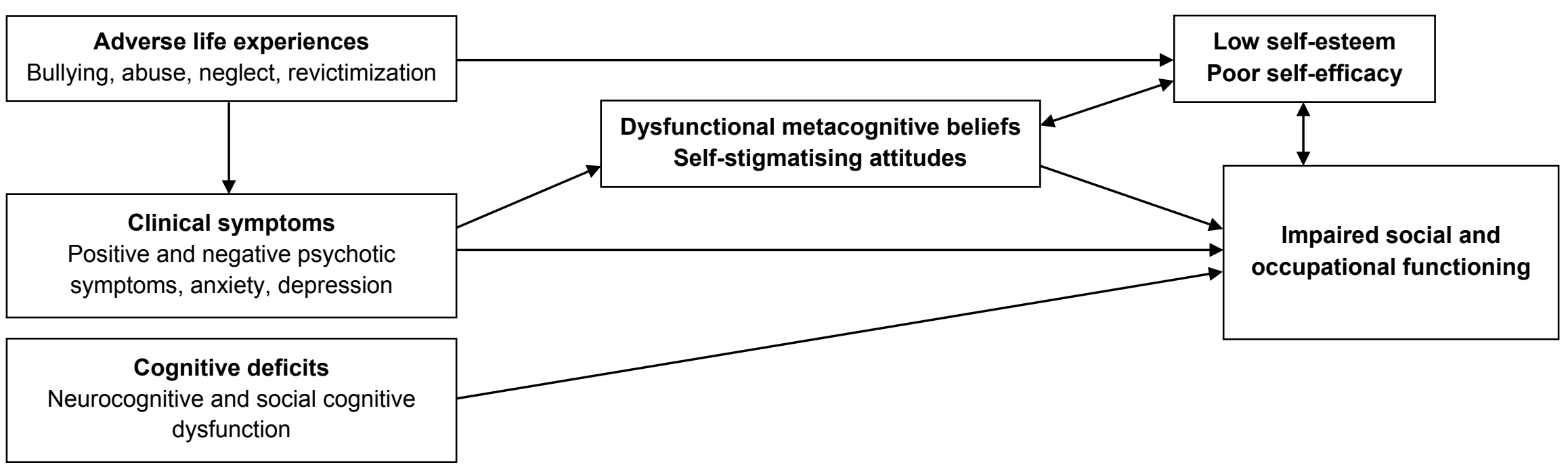

This article is protected by copyright. All rights reserved. 


\section{University Library}

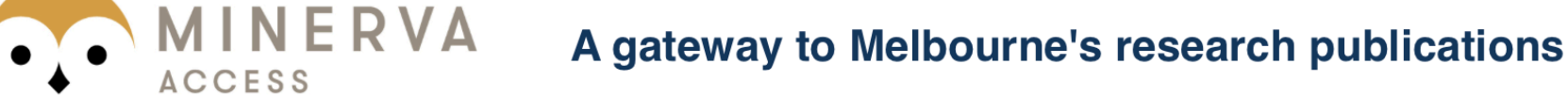

Minerva Access is the Institutional Repository of The University of Melbourne

\section{Author/s:}

Cotter, J;Bucci, S;Drake, RJ;Yung, AR;Carney, R;Edge, D

Title:

Exploring functional impairment in young people at ultra-high risk for psychosis: A qualitative study

\section{Date:}

2019-08-01

\section{Citation:}

Cotter, J., Bucci, S., Drake, R. J., Yung, A. R., Carney, R. \& Edge, D. (2019). Exploring functional impairment in young people at ultra-high risk for psychosis: A qualitative study. EARLY INTERVENTION IN PSYCHIATRY, 13 (4), pp.789-797. https://doi.org/10.1111/ eip. 12560.

Persistent Link:

http://hdl.handle.net/11343/284383 